\title{
EXPERIMENTAL STUDY ON OPTIMIZATION OF BINDER CONTENT IN HIGH PERFORMANCE CONCRETE
}

\author{
Shashi Kumara S.R. ${ }^{1}$, D.L.Venkatesh Babu ${ }^{2}$, B.C. Udayashankar ${ }^{3}$ \\ ${ }^{1}$ Assistant Professor, Department of Civil Engineering, JSS Academy of Technical Education, Bangalore, Karnataka \\ ${ }^{2}$ Professor and Head, Department of Civil Engineering, ACS College of Engineering, Bangalore, Karnataka, India \\ ${ }^{3}$ Professor, Department of Civil Engineering, R.V. College of Engineering, Bangalore, Karnataka, India
}

\begin{abstract}
The concept of particle packing is of basic importance in optimization of concrete mix. The particle packing of a system is a function of particle size distribution, particle shape, surface area, method of compaction, grain size and presence of liquid. While particle packing has a significant influence on the properties of concrete, which contains different sizes of particle, the paste properties are also affected by the interaction between the cementitious particles. Improvement in the packing density of the cement by blending with cementitious materials plays a major role in enhancement of particle distribution, reduction of thermal cracks and in improving mechanical properties of high performance concrete. In the present experimental study, Punkte test conducted to determine the packing density of cement and cementitious material combinations to evaluate optimization in mortar paste. The optimization of different mixes evaluated based on the packing density. It is observed that, Punkte test gives a good indication of optimum packing and significantly helps in designing the mix proportion of the binder materials for high performance concrete.
\end{abstract}

Keywords: Optimization of Concrete, cementitious materials, Punkte test, particle packing

\section{INTRODUCTION}

High performance concrete has increasing used in high-rise construction as a result of decrease in the amount of steel, and thus the dead load. One of the important parameter to achieve high performance in concrete is to reduce the void content in the paste matrix. The cementitious paste, which goes into the voids between the aggregate, containing various sizes and shape of particles in suspension plays an important role in the rheological properties of fresh concrete. Adding fine particles, helps in filling up the voids in the particle structure leaving only minimum space for water.

Particle packing density of concrete mixtures has several advantages for concrete properties in the wet as well as in the hardened state. With a high packing density in the mixture, cement and other particles are close to each other, reducing the space that needs to be filled by hydration products. It has been learnt that the improvement in the packing density of the cementitious materials by blending cement with mineral admixture plays a major role in enhancement of the properties of the mortar produced.

Research in the past has provided clear understanding about the significant role of particle packing on the properties of concrete. [1] conducted study on partial replacement of mineral admixtures on a volume basis to determine packing density using Punkte test. It [2] is apprehended that higher packing densities reduces the water/cement ratio and increases the strength of concrete mixtures. Experiments showed [3] that packing is a function of the particle shape and it affected by the fine aggregate to total aggregate ratio. Review studies [4] shown that, packing is affected by shape, size and proportion of aggregates. Experimental work indicated that, [5] water demand varies with different composition of cementitious materials using Puntke test. Compared [6] to flyash, GGBS has more water demand in Punkte test.

Present work emphasize on the optimization of cement and micro silica in the cement paste for a high performance concrete.

\section{MATERIALS}

\subsection{Cement}

Ordinary 53 grade Portland cement (OPC) with specific gravity of 3.15 and confirming to IS $12269-1987$ was used in this study.

\subsection{Fine Aggregate}

Manufacture sand with a specific gravity of 2.62, and fineness modulus 2.70 conforming to grading zone II as per I.S 383-1970 was used.

\subsection{Coarse Aggregate}

Crushed granite stone with a specific gravity of 2.70 conforming to single sized aggregate having maximum size of $20 \mathrm{~mm}$ with 40 percentage replacement by $12.5 \mathrm{~mm}$ as per IS 383- 1970 used in the present study.

\subsection{Micro Silica}

Commercially available micro silica (supplied by M/S NUCHEMS, Bangalore) with specific gravity 2.20 used in the present study. 


\subsection{Water}

Potable water conforming to the requirements of water for concreting and curing as per IS: 456-2000 used.

\section{EXPERIMENTS PROGRAMME}

\subsection{Punkte Test}

The basic principle of Puntke test is that the water, which is added to the dry materials, fill the voids in between the particles and acts as a lubricant to make the materials compact efficiently. The water, which is in excess after completely filling the voids, appears at the surface of the mixture, indicating the saturation limits. Puntke test involves the selection of binder proportion by volume.

\subsection{Procedure of Punkte Test}

Dry mix of selected volume of solid materials are mixed minimum four times for homogenization. Calculated increment of potable water added to the dry mixture with continuous manual mixing and simultaneous pressing of mixture against the sides of the container wall. Twenty times the container needs to be tapped by keeping on the flow table. This procedure need to repeat for addition of each increment of water until the saturation point (shinning/glossy surface) is reached. The experiment is done in three stages to get the least water required to achieve saturation.

\subsection{Experiment}

Different combination of cement and micro silica are consider for Punkte test to find best combination. Table 1. shows the combination and weight of the cement and micro silica used for Punkte test. The surface texture of the wet combination of cement and micro silica will indicate the saturation of the voids and availability of the excess water in the mixture. Figure 1 and 2 indicating the different surface texture of the wet combination of cement and micro silica.

Table -1: Percentage, weight of cement and micro silica selected for Puntke test

\begin{tabular}{|c|c|c|c|c|}
\hline $\begin{array}{c}\text { Sl. } \\
\text { No. }\end{array}$ & $\begin{array}{c}\text { OPC } \\
\%\end{array}$ & $\begin{array}{c}\text { Micro } \\
\text { silica } \%\end{array}$ & $\begin{array}{c}\text { Weight of } \\
\text { OPC }(\mathrm{gm})\end{array}$ & $\begin{array}{c}\text { Weight of micro } \\
\text { silica (gm) }\end{array}$ \\
\hline 1 & 95 & 05 & 59.85 & 2.22 \\
\hline 2 & 90 & 10 & 56.70 & 4.44 \\
\hline 3 & 85 & 15 & 53.55 & 6.66 \\
\hline 4 & 80 & 20 & 50.40 & 8.88 \\
\hline 5 & 75 & 25 & 47.25 & 11.10 \\
\hline 6 & 70 & 30 & 44.10 & 13.32 \\
\hline 7 & 65 & 35 & 40.95 & 15.54 \\
\hline 8 & 60 & 40 & 37.80 & 17.76 \\
\hline
\end{tabular}

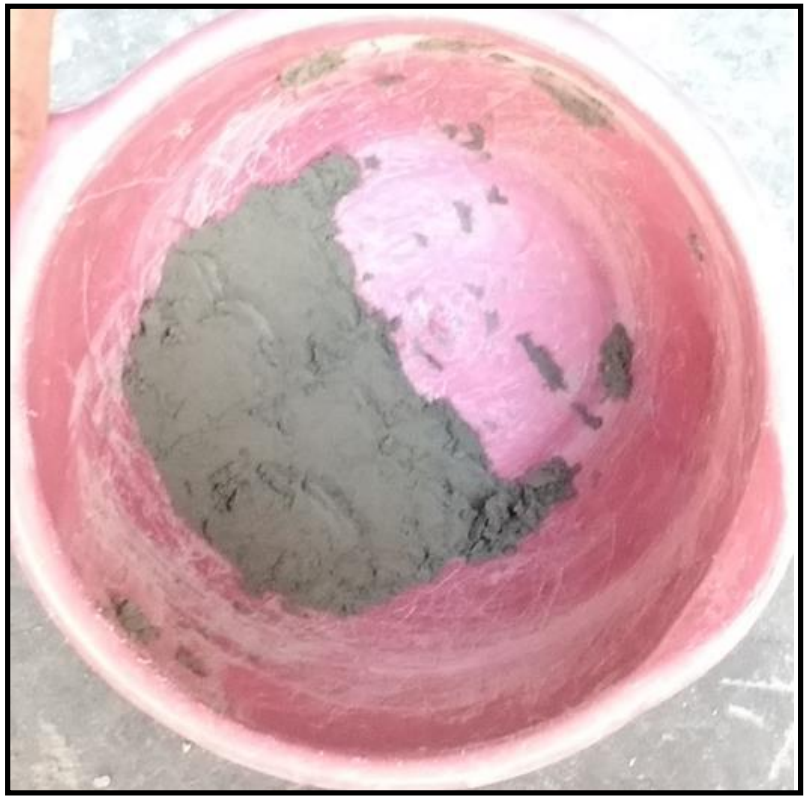

Fig -1: Not statured: Humid soil look

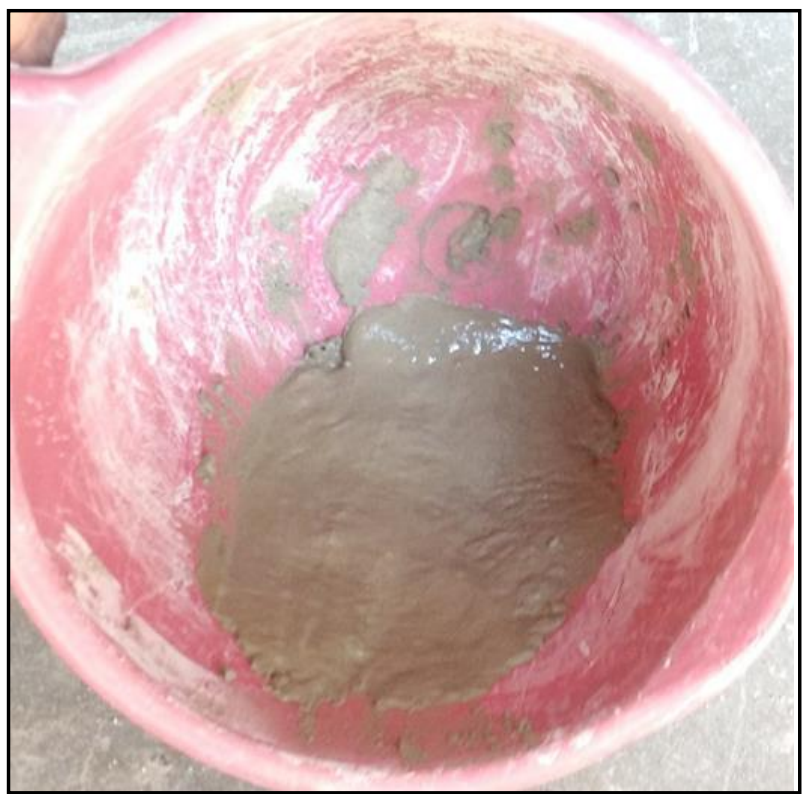

Fig -2: Saturated: Glossy/Sticky surface

The sample calculation of packing density for 80:20 combination of cement and micro silica is shown below: Volume of solid materials $=20 \mathrm{~cm}^{3}$

Mass $=$ specific gravity $\times$ volume

Mass of cement $=3.15 \times 0.80 \times 20 \mathrm{~cm}^{3}=50.40 \mathrm{gm}$

Mass of micro silica $=2.22 \times 0.20 \times 20 \mathrm{~cm}^{3}=8.88 \mathrm{gm}$

Packing density $\left(\varnothing_{\mathrm{p}}\right)=1-\left[\mathrm{V}_{\mathrm{w}} /\left(\mathrm{V}_{\mathrm{s}}+\mathrm{V}_{\mathrm{w}}\right)\right]$

Where,

$$
\begin{aligned}
& =\mathrm{V}_{\mathrm{s}} /\left(\mathrm{V}_{\mathrm{s}}+\mathrm{V}_{\mathrm{w}}\right) \\
& =20 /(20+17) \\
& \emptyset_{\mathrm{p}}=0.540
\end{aligned}
$$

$$
\begin{aligned}
V_{w} & =\text { Volume of water in } \mathrm{cm}^{3} \\
V_{s} & =\text { Volume of solid particle in } \mathrm{cm}^{3}
\end{aligned}
$$




\section{RESULT AND DISCUSSION}

The best combination of the cement and micro silica is determined by observing the surface texture of the wet mixture after Punkte test. Table 2 shows the values of water consumption and packing density for different combination.

Table -1: Water requirement and Particle density for each combination

\begin{tabular}{|c|c|c|c|c|}
\hline $\begin{array}{c}\text { Sl. } \\
\text { No. }\end{array}$ & OPC \% & $\begin{array}{c}\text { Micro } \\
\text { Silica \% }\end{array}$ & $\begin{array}{c}\text { Water } \\
\text { requirement } \\
\left(\mathrm{cm}^{3}\right)\end{array}$ & $\begin{array}{c}\text { Packing } \\
\text { density }\end{array}$ \\
\hline 1 & 95 & 05 & 19.00 & 0.512 \\
\hline 2 & 90 & 10 & 18.50 & 0.519 \\
\hline 3 & 85 & 15 & 18.00 & 0.526 \\
\hline
\end{tabular}

\begin{tabular}{|c|c|c|c|c|}
\hline 4 & 80 & 20 & 17.00 & 0.540 \\
\hline 5 & 75 & 25 & 17.30 & 0.536 \\
\hline 6 & 70 & 30 & 17.30 & 0.536 \\
\hline 7 & 65 & 35 & 17.40 & 0.534 \\
\hline 8 & 60 & 40 & 17.50 & 0.533 \\
\hline
\end{tabular}

The wet combination of 80 percentage of cement and 20 percentage of micro silica required less water and attained maximum packing density. Graph 1 indicates the various packing density with different combination of cement and micro silica.

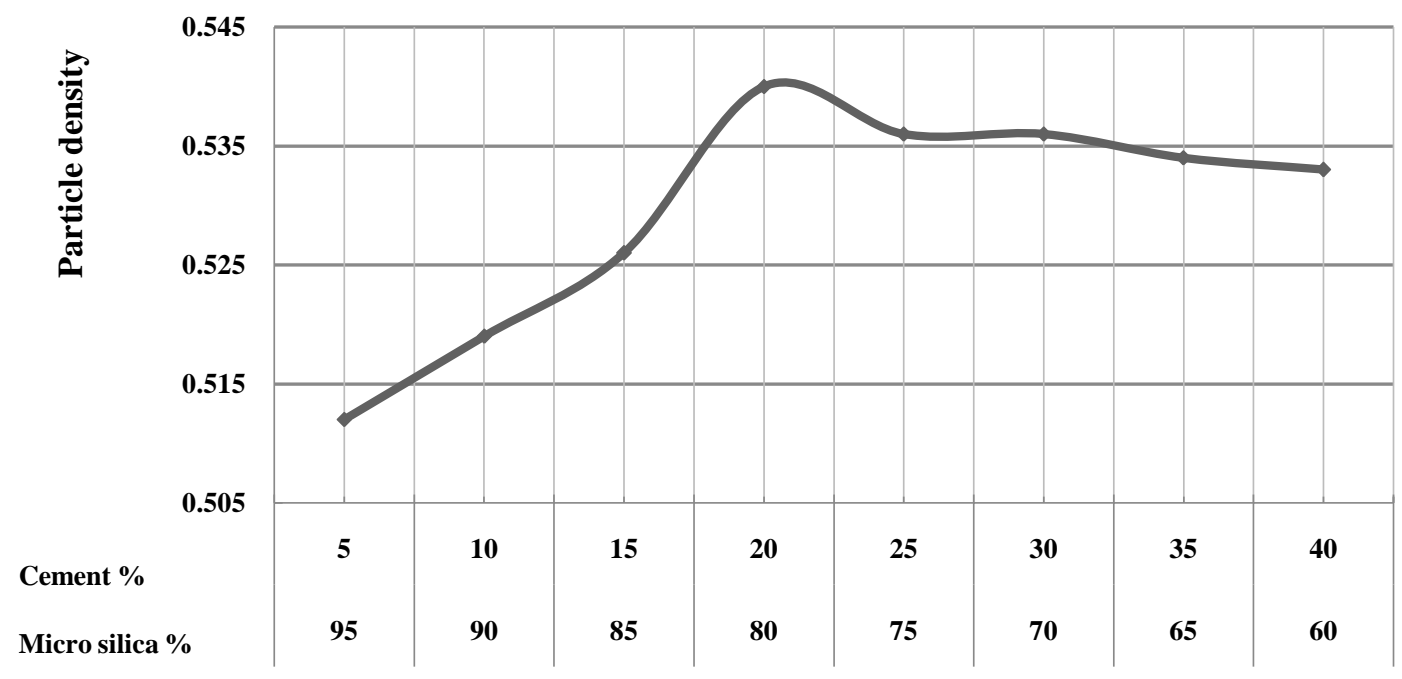

Percentage combination of binder content

Graph 1 Packing density of binder content for different percentage of cement and micro silica

It is observed that the among different combination of cement and micro silica, $80 \%$ of cement and $20 \%$ of micro silica shows the highest packing.

\section{CONCLUSION}

In high performance concrete it is extremely necessary to ensure the use of fine and ultrafine materials along with cement. Particle size distribution is not only beneficial for the water demand, but it can also decrease the space between the cement particles. In the present study, Punkte test provide the experimental solution to find the best combination of cement and micro silica among different combination. Based on experimental result following conclusion can be drawn:
- Punkte test provide the solution for optimization of cementitious materials in wet condition, which closely resembles the real situation of cementitious materials in paste.

- Increased packing density, improves the strength of concrete.

- A optimized paste matrix, results in high packing density and restrain the amount of shrinkage and creep.

- From the result, it is evident that, the water requirement is increases with increase in micro silica content.

- Packing density, increases linearly upto, the wet mix reaches the saturation. Beyond the saturation point, the packing density decreases in a slow rate. 
- Visual observation of the surface texture in Punkte test is the quick and reliable method to find the optimization between cement and mineral admixtures.

- Among all different combinations, the 80:20 combination of cement and micro silica has exhibit the highest packing density.

\section{ACKNOWLEDGEMENTS}

The authors acknowledge the UG student and the management for their support during successful conduction of this experimental work.

\section{REFERENCES}

[1] Nanthagopalan P and Santhanam M (2008) A new approach to optimization of paste composition concrete, The Indian Concrete Journal, Vol. 82, pp. $11-18$

[2] Sonja A.A.M. Fennis, Joost C. Walraven, "Using particle packing technology for sustainable concrete mixture design" Delft University of Technology, the Netherlands, HERON Vol. 57 (2012) No. 2, pp. 73101.

[3] Mohammed H. Mohammed, Mats Emborg, Roland Pusch, Sven Knutsson, (2012), "Packing Theory for Natural and Crushed Aggregate to Obtain the Best Mix of Aggregate: Research and Development" ,World academy of science engineering and technology international journal of civil, environment, structural, construction and architectural engineering vol:6, No:7, 2012, pp. 479485.

[4] Mangulkar M. N., Dr. Jamkar S.S. (2013), "Review of Particle Packing Theories Used For Concrete Mix Proportioning", International journal of scientific \& engineering research volume 4 , issue 5, may -2013 , ISSN 2229-5518, pp. 143-148.

[5] Wolfram Schmidt, "Rheologische Messungen an mineralischen Baustoffen". BAM Federal Institute for Materials Research and Testing, Berlin, 22. Kolloquium und Workshop, Regensburg (2013), pp.1-47.

[6] H. J. H. Brouwers (2006), "Particle-size distribution and packing fraction of geometric random packings. Faculty of Engineering Technology, University of Twente, P.O. Box 217, 7500 AE Enschede, The Netherlands Received 6 March 2006; published 26 September, The American physical society, Physical review E 74, 031309, pp. 031309:1-14.

[7] Ambuja Technical Literature Series 156, Particle Packing In High Performance Concrete Using Punkte Test (2015).

[8] F. De Larrard and T. Sedran, "Optimization of UltraHigh Performance Concrete by the use of a Packing Model" Cement and Concrete Research, Vol. 24, No. 6, 1994, pp.997-1009.

[9] Vivian Wong, Ka Wai Chan, Albert Kwok Kwan(2013), "Applying Theories of Particle Packing and Rheology to Concrete for Sustainable
Development", Department of Civil Engineering, The University of Hong Kong, Hong Kong, China. Research paper 10.5592/otmcj.2013.2.3, pp844-851.

[10] Abibasheer Basheerudeen and Anandan Sivakumar (2014) Particle Packing Approach for Designing the Mortar Phase of Self Compacting Concrete, SMBS, VIT, Vellore, Tamilnadu, India, Engineering Journal Volume 18, Issue 2, DOI:10.4186/ej.2014.18.2.127, pp. 127-141.

[11] R. Yu, P. Spiesz, H.J.H. Brouwers, "Development of an eco-friendly Ultra-High Performance Concrete (UHPC) with efficient cement and mineral admixtures uses". Department of the Built Environment, Eindhoven University of Technology, P.O. Box 513, 5600 MB Eindhoven, The Netherlands. Cement \& Concrete Composites 55 (2015) pp.383-393.

[12] Karthika Kishore Koka, Shashi Kumara S.R, D.L .Venkatesh Babu" Steel fibre reinforced latex modified concrete International Journal of Engineering Research \& Technology (IJERT),ISSN: 2278-0181,Vol. 3 Issue 9, September- 2014, pp 12731276.

[13] Rajarajeshwari B Vibhuti, Radhakrishna, Aravind N (2013), "Mechanical Properties of Hybrid Fiber Reinforced Concrete for Pavements", International Journal of Research in Engineering and Technology, eISSN: 2319-1163, pISSN: 2321-7308, 244-247.

\section{BIOGRAPHIES}

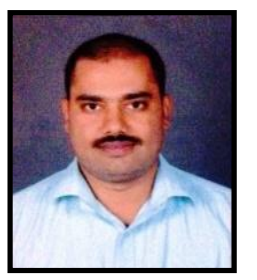

Prof. Shashi Kumara S.R. is working as Assistnat Professor at Department of Civil Engineering, JSS Academy of Technical Education, Bangalore, Karnataka, India. He has published more than 8 technical papers in the reputed journals. Formerly he was working as Senior Engineer at M/S Ultra Tech Cements, Mysore, Karnataka, India

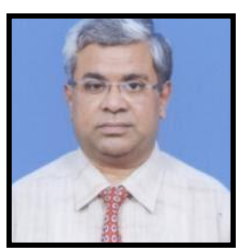

Dr. D.L. Venkatesh Babu has more than 30 years of academic experience at different levels. He has published more than 50 technical papers in international, national journals and conferences. Presently he is heading the department of civil engineering, ACS College of Engineering, Bangalore, Karnataka, India.

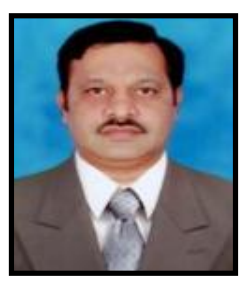

Dr. B.C. Udayashankar, has more than 25 years of academic experience at different levels. He has published several technical papers in international, national journals and conferences. He was the head of civil engineering department, RVCE, Bangalore. Presently he is working as Professor at department of civil engineering, R.V. College of Engineering, Bangalore, Karnataka, India. 